writer conjectures it to be a hybrid between lanata and populi. tolia, var. leucanthus.

If any one will look at the plates to which I have referred, he may satisfy himself of the astonishing diversity of these forms. In Gard. Mag. 1839, p. 430, is an early record of the appearance of the new seedlings at shows. At the Caledonian Horticultural Show, the Cinerarias "were very brilliant, and partook of novelty." The names of the seedlings successful, including waterhousiana, are given. At the beginning of the forties the named kinds became very numerous, and were at first offered at high prices in the trade advertisements. Henderson and Ivery were the two chief English cultivators at that time.

During this period, $1830-1840$, the progress was very rapid, and there can be no doubt that the florists'Cinerarias came into existence within some ten or twelve years. Such a plate as that in Four. d'hort. Gand, 1846 , shows the ordinary kinds much as we know them. From those plants up to the perfected plant of ten years ago, the change was undoubtedly slow and gradual. The alterations have consisted chiefly in increase in size and symmetry of the flower, and in promotion of compactness of habit (see, e.g., Glenny, Ann. of Hort. 1850, p. 37, also Gard. Chron. I879 (I), p. 532).

The next point is of some interest. As compared with other "improved" herbaceous plants, the Cineraria is a little peculiar in the fact that it is now generally raised from seed. This is done partly to ensure that the plants shall not be overgrown, and partly to avoid green fly, a pest to which these piants are specially liable. In consequence of this, the old "named" kinds, that is to say, kinds propagated by asexual methods, went out of fashion, though till lately they still had supporters. It was found that seeds of good strains could be fairly relied on -not, of course, to reproduce the form of their particular parents, but to give fine plants. For instance, Henderson, Scot. Gard. i. 1852 , p. 22, says : "in raising seedlings you should select three or four dwarf varieties, which number is quite sufficient to produce all the different colours." In Gard. Chron. I887 (I), p. 549, are some interesting particulars of the methods used by Mr. James, to whom the later improvement of the plant in England is largely due. The plants of each colour are grouped in blocks, and the bees are freely admitted to the houses. It is not found necessary to separate the plants further, and in saving seed all the colours are mixed together. In the case of the Cineraria therefore, as in that of Calceolarias, Begonias, and other plants much grown from seed, it is desirable not only to create a fine variety of which the stock can at once be multiplied asexually, but also to raise a good strain of which the seedlings come fairly true. The latter process may undoubtedly often take time.

Even in recent times a "sport" has been recorded. In Gard. Chron. 1880 (1), p. 277 , it is stated that Mr. James "' has succeeded in obtaining a new 'break' that promises to be the forerunner of another host of new flowers. The colours of the flower do not shade off into one another, as is usually the case, but are arranged in bold and well-defined belts. .... We understand that it flowered for the first time last season, and that it has reproduced itself from seed." A figure is given.

To these particulars might be added many more, relating to the origin of double varieties, variations in the foliage, and other matters. The foregoing notes of the history must, I think be taken to show (I) that the modern Cinerarias arose as hybrids derived from several very distinct species; $(2)$ that the hybrid seedlings were from the first highly variable ; (3) that "sports" of an extreme kind appeared after hybridisation in the early years of the "improvement" of these plants; (4) that the subsequent perfection of the form, size and habit has proceeded by a slow process of selection. Mr. Dyer's statement that the modern Cinerarias have been evolved from the wild $C$. cruenta "by the gradual accumulation of small variations" is therefore, in my judgment, misleading, for this statement neglects two chief factors in the evolution of the Cineraria, namely, hybridisation and subsequent "sporting."

I have ventured to deal with this case because it seems to be generally supposed by those not acquainted with the facts, that the origin of the modern florists' flowers has in general been very gradual. As a matter of fact it would, I believe, be more true to say that the new departures have in general been at first very rapid, subsequent improvement being commonly slow. "Sporting," usually after hybridisation, has been the chief factor in the production of these new developments, just as in the case of the Cineraria. To speak of no more, I may refer to the new forms of Begonia, of Giadiolus, and of Erica now so familiar. With what special propriety the Cineraria was chosen by $\mathrm{Mr}$. Dyer to support his contention is not evident to me.

Whether any of these sports exhibit the phenomenon of organic stability I cannot now discuss.

St. John's College, Cambridge, April 17.

\section{The Age of the Earth.}

IN Dr. Hobson's letter on this subject, he confuses the argument by the introduction of a new factor (never alluded to in the former discussion, or in my theory as stated in "Island Life"), the bulk or volume of the matter deposited. This has nothing whatever to do with the practical problem, because it is admittedly impossible to form any estimate of the total bulk of all the stratified rocks of the earth during all geological time; while it is equally impossible to form any estimate of the total bulk of the denuded matter, since we have no clue whatever to the number of times the same areas have been again and again denuded. But the maximum thickness of the same rocks, compared with the average rate of denudation, and the coincident maximum rate of deposition, do furnish materials for an estimate, since they can all be approximately determined from actual observation ; and the result is what $I$ have given. If Dr. Hobson had referred to the former discussion he would have avoided imputing to me "fallacies" which I never made. I never said a word about " equal bulks" of material being deposited in less time than they were denuded. But, as the only available data are those of thickness, not bulk, then it is clear that, if the area of deposition is one-nineteenth of the area of denudation, the rate of deposition of a known thickness of rocks will be nineteen times as great as the known rate of denudation. It was necessary for me to point this out when first discussing the subject, because one eminent writer had made the rate of deposition less than the rate of denudation, because the water-area is greater than the land-area of the globe; while an eminent geologist has quite recently taken the rates of denudation and deposition as being equal. If, however, the area of deposition is very much less than the area of denudation, which is now admitted to be the fact, then the rate of deposition per foot of thickness will be many times greater than the rate of denudation.

I should not have thought it necessary again to state this very obvious conclusion, had not Prof. Sollas, while so clearly pointing out Dr. Hobson's misconception as to the area over which the maximum thickness of the strata extended, omitted to refer to the confusion he has now for the first time introduced into the problem, by references to the bulk or volume of the sedimentary rocks, a factor which all previous writers have seen to be wholly beyond even an approximate determination.

Alfred R. Wallace.

So little is really known about the earth's age that any additional mode of approximating to it; however rough, may possess some value. The following method of finding a lower limit is, with one or two alterations, the same as that given in a paper in the Geological Magazine for 1887 (p. 348). It depends, not on the rate of denudation, but on the rate of subsidence within the area of sedimentation.

Part of the sediment brought down by a river is used for keeping the surface of the delta close to the level of the sea; and the fact that the deposits formed from it are generally shallow-water deposits, shows that the amount of sediment is, as a rule, sufficient or more than sufficient for the purpose. The remainder of the sediment is carried out seawards, and enlarges the delta laterally.

If there were no surplus sediment, it is evident that the mean rate of subsidence over the delta would be obtained by dividing the volume of the sediment brought down annually by the river by the area of the delta. But if there be an excess of sediment, then the same quotient will give a value greater than the mean rate of subsidence, for only part of the sediment is used for keeping the delta-surface in shallow water. In the case of the Mississippi, the amount of sediment brought down annually is $7,459,267,2 \mathrm{co}$ cubic feet, and the area of the delta I 2,300 square miles, or $342,204,320,000$ square feet; so that the mean rate of subsidence is not greater than $\frac{1}{46}$ of a foot per $y \leqslant a r$, or $2 \cdot 18$ feet per century.

Prof. Sollas estimates the total maximum thickness of the different layers of sediment since the beginning of Cambrian 